Special issue of the 3rd International Conference on Computational and Experimental Science and Engineering (ICCESEN 2016)

\title{
The Design Steps of a Hybrid Energy System
}

\author{
M.E. ŞAHIN ${ }^{a, *}$ AND H.İ. OKUMUŞ ${ }^{b}$ \\ ${ }^{a}$ Department of Electrical and Electronics Engineering, Recep Tayyip Erdoğan University, Rize, Turkey \\ ${ }^{b}$ Department of Electrical and Electronics Engineering, Karadeniz Technical University, Trabzon, Turkey \\ In this paper the design stages of a mixed photovoltaic-wind energy system, supplied with solar and wind \\ energy was discussed. First, general information about the employed wind turbines and solar panels is given and \\ their basic characteristics are addressed. Then, essential information for the system setup and measurements was \\ given. The system setup, operation of the system, the ways to store energy and how energy is consumed were \\ described and the results were interpreted. This study serves as a background for the experimental studies in the \\ future.
}

DOI: 10.12693/APhysPolA.132.1160

PACS/topics: 88.05.Ec, 88.05.Gh, 88.05.Rt

\section{Introduction}

When the wind and solar energy potential of our region is considered, it is seen that the installation of a standalone system, independent from the network, is very difficult and costly [1-3]. Therefore, it is thought that a system which can use both wind and solar energy can be more economical. In this case, the energy will be supplied from the Sun on the lack of wind energy or from the wind on the lack of sun energy $[4,5]$.

In this study, a wind turbine and solar panels were placed independently in a convenient locations in laboratories and near department buildings. While a large part of the work was funded by TÜBITAK research project number 111E292, the rest was funded by sponsors. One of the aims of the study is to use the built system as an actual power source for testing the studied power electronic systems [6].

There are also other useful reasons for building solar panels and wind turbines as parts of an independent system. The most important one is the difficulty of building systems on the roof to hold the system steady in windy weather conditions. It is easy to intervene and to take the necessary measures in the discussed system [7].

One of the most important considerations for installation is to select the appropriate panels and turbine for required power [8]. For this purpose, as a preliminary study, measurements were taken from the solar panels which would be used as the main energy source and the amount of energy that could be received in the worst conditions was calculated [9-11]. In addition, the most suitable turbine for the intended location was established by examining the characteristics of the wind turbines [12].

Finally, it is aimed to use the surplus energy by storing it in suitable batteries, and to use it later when there will be no sufficient energy. Suitable power inverters were added to the system to feed alternating current loads

*corresponding author; e-mail: mustafaerginsahin@yahoo.com and it was intended to ensure an easy use of the necessary home equipment. The system components were gathered in an appropriate cabinet, forming a power unit. System was arranged to use surplus energy for illumination at nights.

\section{Hybrid system introduction and installation}

In this section, the technical studies of the hybrid system, carried out in the establishment phase, which could not be addressed in the introduction part, and the general and technical characteristics of the system are presented. Firstly, the choice of the system location was made. Preliminary studies and measurements of the intensity of wind flow and solar irradiation were carried out because there are many wooded and residential areas in the campus. Thus, the most suitable place was identified to set up the designed clean energy home. In the next stage, the installation of the $2.40 \times 4 \times 2 \mathrm{~m}^{3}$ container, suitable for our purposes was carried out.

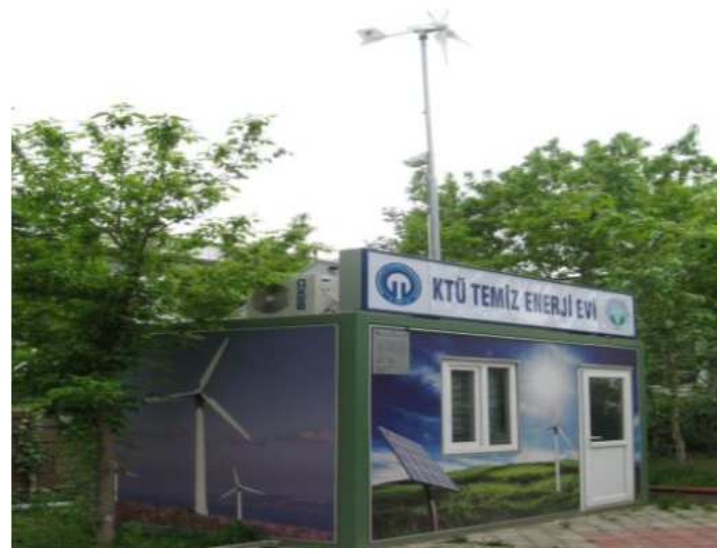

Fig. 1. The general image of realized clean energy house.

For the designed system to fit the surroundings, the container was covered with pictures. General view of the designed system, in the form of a house, which was installed in front of the Electrical and Electronics Engineering 
department of KTU, is given in Fig. 1. Technical information about the established system is given in Table I.

TABLE I

Technical data of hybrid energy system.

\begin{tabular}{c|c}
\hline \hline Parameter name & Value \\
\hline Total power & $2400 \mathrm{~W}$ \\
Solar panels power & $100 \times 4=400 \mathrm{~W}$ \\
Wind turbine power & $400 \mathrm{~W}$ \\
Take-off wind speed & $2 \mathrm{~m} / \mathrm{s}$ \\
Bus voltage & $24 \mathrm{~V}$ \\
Battery capacitance & $100 \mathrm{~A} \mathrm{~h}$ \\
Pure sine wave inverter power & $1500 \mathrm{~W}$ \\
Modified sine wave inverter power & $800 \mathrm{~W}$ \\
DC night lighting loads & $150 \mathrm{~W}$ \\
Maximum air conditioning load & $800 \mathrm{~W}$
\end{tabular}

\subsection{Presentation and installation of the employed wind turbine}

A suitable mast was selected and its installation was carried out for the wind turbine. The wind turbine is mounted on the mast $10 \mathrm{~cm}$ in diameter with the height of $10 \mathrm{~m}$. The wind turbine has weight of about $22 \mathrm{~kg}$ and five wings. It can generate $400 \mathrm{~W}$ of output power at rated speed and voltage.

The wind turbine is selected so that it can be capable of taking on at low speeds, since the residential area does not get enough wind and is covered with woodlands. Wind turbine has five wings and a value of average power constant of $C_{\mathrm{P}} \geq 0.36$. The rotor diameter is $1.55 \mathrm{~m}$. In addition, it works more efficiently, because it is activated at wind speed of $2 \mathrm{~m} / \mathrm{s}$.

It is difficult to measure wind speed in different fields and at different altitudes from the ground level during the design steps. Therefore, the following equation was used. In this equation, $V_{\mathrm{R}}$ is the measured reference wind speed and $V_{\mathrm{T}}$ is the wind velocity, calculated theoretically, $\alpha$ represents the coefficient of friction [8] due to grounds roughness.

$$
V_{\mathrm{T}}=V_{\mathrm{R}}\left(\frac{h_{\mathrm{T}}}{h_{\mathrm{R}}}\right)^{\alpha} \text {. }
$$

Wind speed was measured three meters above the ground as $3 \mathrm{~m} / \mathrm{s}$ and coefficient of friction is selected to be $\alpha=0.3$ for a wooded area terrain with buildings. For these values, 10 meters above the ground wind speed is calculated to be $4.3 \mathrm{~m} / \mathrm{s}$, using Eq. (1).

The calculated theoretical wind speed can be used to calculate power of a wind turbine with the help of Eq. (2). In this equation, $C_{\mathrm{P}}$ is the power factor constant of turbine, $\rho$ is the air density $\left(1.225 \mathrm{~kg} / \mathrm{m}^{3}\right), A$ is the area swept by the blades and $V$ represents the speed of the wind.

$$
P_{\text {avg }}=\frac{1}{2} C_{\mathrm{P}} \rho A V^{3} .
$$

In this case, for $C_{\mathrm{P}} \geq 0.36, \rho=1.225 \mathrm{~kg} / \mathrm{m}^{3}, A=$ $1.88 \mathrm{~m}^{2}$, and $V=4.3 \mathrm{~m} / \mathrm{s}$, the average wind power is calculated as $P_{\text {avg }}=33.6 \mathrm{~W}$. This is the theoretical power which can be produced by the generator for low wind speeds. If these calculations are repeated for $V=12 \mathrm{~m} / \mathrm{s}$ nominal wind speed, the average wind power is found as $P_{\text {avg }}=716.32 \mathrm{~W}$.

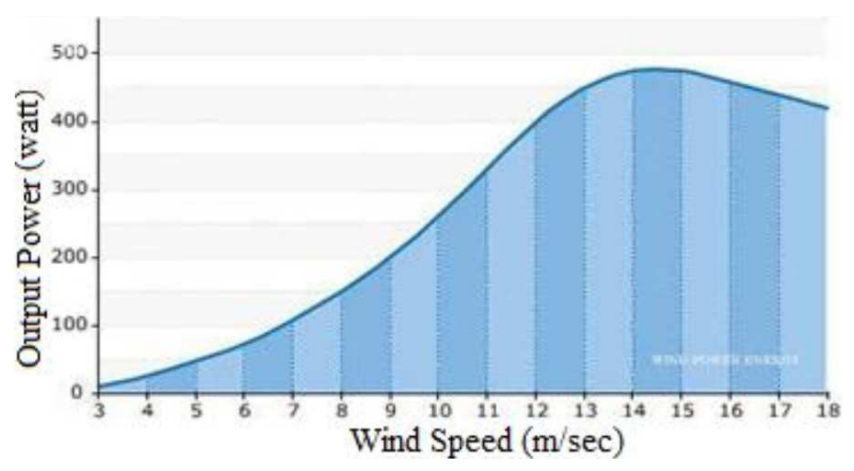

Fig. 2. Power produced by the wind turbine as a function of the wind speed.

The generator of the wind turbine is a three-phase brushless type generator with more robust neodymiumiron magnets used as permanent magnets. The desired power can be provided at $12 \mathrm{~m} / \mathrm{s}$ wind velocity. It can run smoothly up to wind speed of $50 \mathrm{~m} / \mathrm{s}$. The power vs wind speed curve of the employed wind turbine is given in Fig. 2. Here, the output power of the generator at wind speed of $12 \mathrm{~m} / \mathrm{s}$ is seen to be $400 \mathrm{~W}$ [12]. The difference between the indicated average power $P_{\text {avg }}$ and the values given by the curve is due to the efficiency of the wind turbine. This efficiency is

$$
\eta=\frac{P_{\text {out }}}{P_{\text {avg }}} 100 \%=\frac{400}{716.32} 100=55.8 \% .
$$

Another feature of the wind turbine is that it can find the direction of the wind due to its balance tail and can operate with high efficiency, continuously. Wind turbine is resistant to high wind speed and has a feature of turning wind energy into electrical energy. However, the turbine should be installed in a stable location and precautions must be taken against shaking and vibration. Therefore, turbine poles are made of poured concrete anchors, $50 \times 50 \mathrm{~cm}^{2}$ in size and $70 \mathrm{~cm}$ deep. In addition, the hinge system is made for the pole to be easily raised and lowered. At three different points in the middle of the pole, rope tensioning is done to provide full upright standing and to prevent damage from wind shaking.

\subsection{Solar panel installation and measurements}

The other step of the installation process is mounting the solar panels and transmission of the generated power. The four PV panels, which have $100 \mathrm{~W}$ output power, each, are mounted on an adjustable surface. The image of the panels is shown in Fig. 3a and their connection circuit is shown in Fig. 3b.

In the designed system, the orientation of solar panels is not constant and can be adjusted to $15^{\circ}, 30^{\circ}$, and $45^{\circ}$ 
angles, by means of a moving platform. From the measurements and calculations it is accepted that in winter at $45^{\circ}$, in spring and autumn at $30^{\circ}$, and in summer at $15^{\circ}$ the solar beams impact with the solar panels under a fairly right angle $[8,13]$. The platform is also designed to get into different configurations by connecting the PV panels in series and in parallel. Series and parallel connections are made using special MC4 connectors. A two color wire was used for power transmission, which has $4 \mathrm{~mm}^{2}$ cross section and was specially designed according to heat and other output effects.

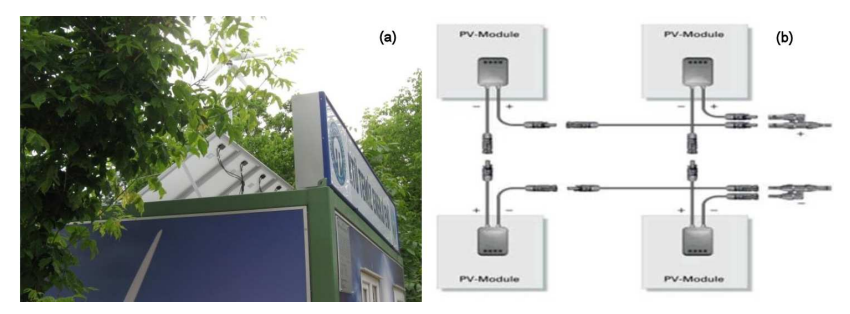

Fig. 3. The solar panels, (a) mounting, (b) wiring diagram.

Solar panel of SUNRISE brand, model SRM540100 100W, having a single crystal structure, was used for pre-measurements, to calculate solar panels power for the regional climate conditions [10]. The PV panels data sheet values are given in Table II and the experimental setup is given in Fig. 4.

\section{TABLE II}

Catalog data of the employed solar panels.

\begin{tabular}{c|c}
\hline \hline Parameter name & Value \\
\hline Maximum power $\left(P_{\mathrm{m}}\right)$ & $100 \mathrm{~W} \pm 3 \%$ \\
Open circuit voltage $\left(V_{\mathrm{oc}}\right)$ & $24.35 \mathrm{~V}$ \\
Short circuit current $\left(I_{\mathrm{sc}}\right)$ & $5.51 \mathrm{~A}$ \\
Maximum power voltage $\left(V_{\mathrm{m}}\right)$ & $19.80 \mathrm{~V}$ \\
Maximum power current $\left(I_{\mathrm{m}}\right)$ & $5.06 \mathrm{~A}$ \\
Module and cell efficiency [\%] & $15.6-18.43$ \\
Cell type - Si mono crystal & $125 \times 125[\mathrm{~mm}]$ \\
Cell number $(\operatorname{Pcs})$ & $40(4 \times 10)$ \\
Operation temperature $\left[{ }^{\circ} \mathrm{C}\right]$ & $-40,+85$
\end{tabular}

The intensity of sunlight for the established experimental setup was measured with a help of Luxmeters. However, these values cannot be used directly because solar irradiation $\left(\mathrm{W} / \mathrm{m}^{2}\right)$ and luminous intensity (lux) have different units. Here, a conversion factor was used between the intensity of solar irradiation and illuminance $[9,11]$. The average panel temperature was measured by measuring the temperature of the upper and lower panels, using two thermocouples.

The current and voltage of the solar panels were measured under different loads and the obtained $I-V$ and $P-V$ curves are shown in Fig. 5a and b. These measurements were made on different days and for lowest lux hours the intensity of solar irradiation in sunlight

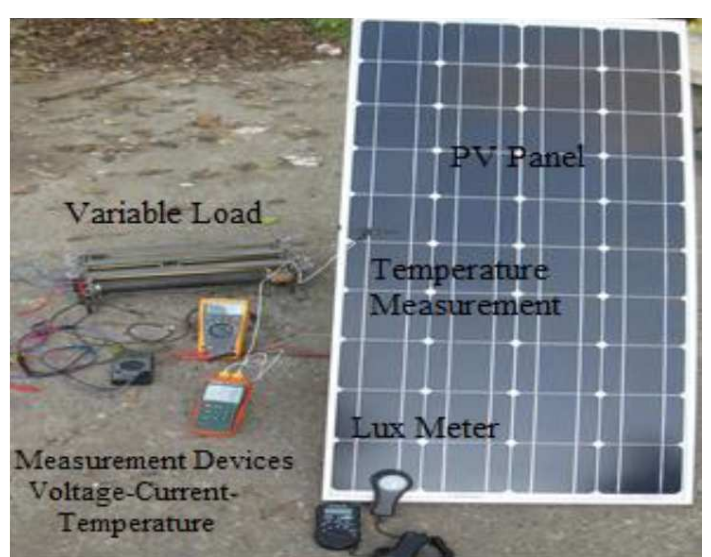

Fig. 4. The measurement and test setup of solar panels.

were determined to be 95000 and 70000 lux in December. Average panel temperature was measured as $50^{\circ} \mathrm{C}$ and $35^{\circ} \mathrm{C}$ in two different measurements [7].
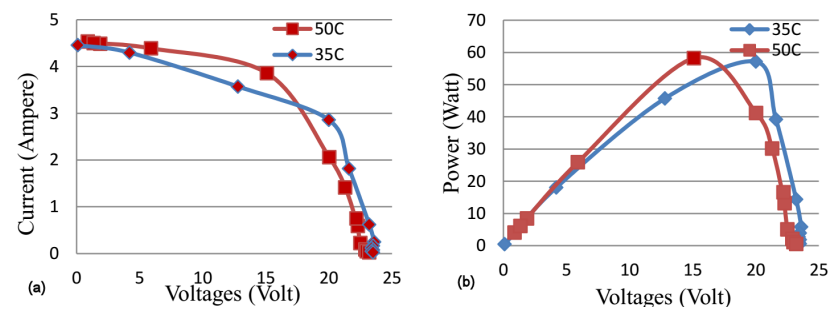

Fig. 5. Current-voltage (a) and power-voltage measurements (b) of solar panels.

In our measurements of solar panels, the panel curves have reached the expected catalog data, however, could not reach the maximum power in low irradiation [14]. The amount of power for the lowest solar irradiation in a year was found. With the increase in the irradiation, the amount of power increases slightly [17]. Another obtained result of the measurements is that the voltage of the solar cells maximum operating point changes between 15$20 \mathrm{~V}$. Therefore, it is impossible for the solar panels to feed a $24 \mathrm{~V}$ battery directly. To eliminate the need of increasing the voltage, solar panels are connected serially or a buck-boost converter can be used.

\subsection{Connection of battery and loads}

After the installation of the wind turbine and the solar panels, the energy should be stored in the batteries and the required loads should be properly supplied. The charge of the batteries and control of the system were carried out by a charge controller. This controller, which is fed by the solar and the wind power, can feed the loads while charging $[15,16]$. General connection diagram of the entire system is given in Fig. 6 .

Here are other issues that must be addressed, regarding battery capacity and connectivity. Because the system voltage and bus voltage are considered to be $24 \mathrm{~V}$, 


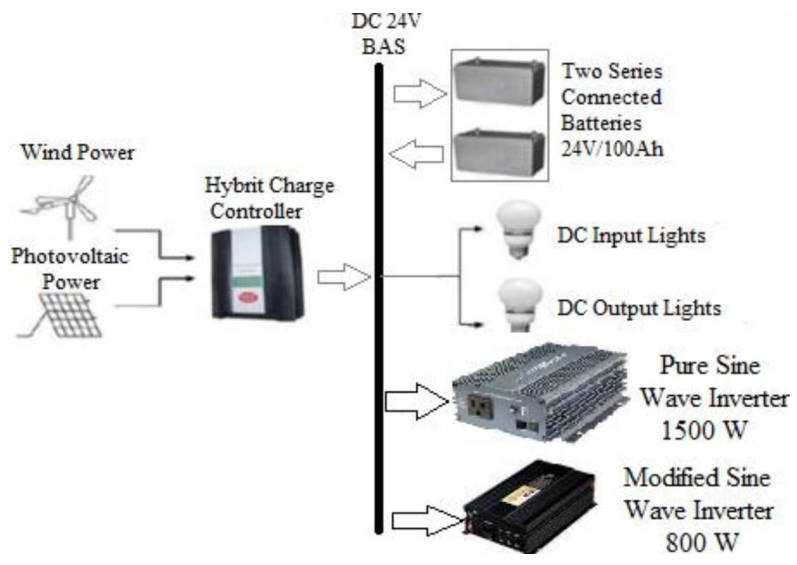

Fig. 6. The wiring diagram of the entire system.

two dry batteries, which are 100 Amp-hours, $12 \mathrm{~V}$, are connected in series to provide $24 \mathrm{~V}$ bus voltage. These batteries have energy storage capacities of $2.4 \mathrm{kWh}$. In addition to two cables, $10 \mathrm{~mm}^{2}$ cross-section, of different colors for the plus and minus terminals, are used to avoid excessive voltage drop. The battery is connected in series with the 100 A fuse, for protection against short circuits. A monitor, along with measuring devices, other devices and communication systems were placed inside a cabinet, as shown in Fig. 7.
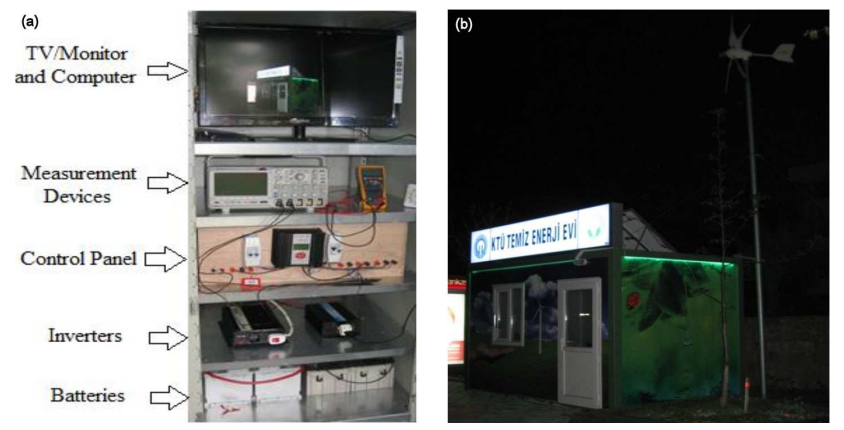

Fig. 7. Energy control cabinet (a) and a night view of clean energy house (b).

Finally, improper usage of the stored energy and exceedingly fast discharging of the battery will damage the system. Therefore, selection of appropriate load and over current protection is required. In the first stage, the energy stored in the batteries is used by selected loads, appropriate for $24 \mathrm{~V} \mathrm{DC}$ voltage. These loads are the boards interior lighting, LED lighting, projector lighting and interior lighting, which are all running on $24 \mathrm{~V} \mathrm{DC}$ voltage. When all these devices are activated, the total current and power are $6 \mathrm{~A}$ and about $150 \mathrm{~W}$, respectively. Therefore, sufficient energy is available in the batteries for these devices, which are only activated at night and are able to operate normally until the day dawns. A night view of the designed hybrid energy house is given in Fig. 7.
In this study, a $1500 \mathrm{~W}$ pure sine wave inverter and a $800 \mathrm{~W}$ modified sine inverter were also fed with stored energy and energy obtained from solar and wind energy. With these inverters, not only the lighting, but also the operation of appliances, such as refrigerator, television, air conditioning, computers etc., is provided. This way, the measurement and test instruments which are used in other studies can be also provided by the energy of the designed system. With this hybrid power system, other scientific studies can also be performed.

\section{Conclusions}

In this study, the design steps of a system supplied by a mix of photovoltaic and wind energy were discussed. Firstly, general information about the employed solar panels and wind turbine were provided, the basic features were mentioned and how the system was built was explained in details. The system was tested to work correctly, by making a series of measurements and by connecting several loads to the system. Wind and solar power-related measurements and calculations and plots are presented in this study. The effect of temperature on efficiency of solar cells and effect of wind on wind turbine efficiency are investigated. The standalone hybrid system is realized experimentally in this study. With this hybrid power system, other scientific studies are performed and continue to be realized.

\section{Acknowledgments}

This study was supported by The Scientific \& Technological Research Council of Turkey (TUBITAK), with project no. 111E292. The authors wish to thank TUBITAK for the support.

\section{References}

[1] Republic of Turkey Meteorological Agency, Sun Time for Trabzon Province, www.dmi.gov.tr/ veridegerlendirme/il-ve-ilceler-istatistik.asp, 21 September 2011.

[2] Z. Şen, A.D. Şahin, Renewable En. 12, 169 (1997).

[3] I. Atılgan, J. Faculty Engin. Architect. Gazi Univ. 15, 1 (2000).

[4] M.E. Şahin, Ph.D. Thesis, Karadeniz Technical University, Turkey 2014.

[5] A.A. Jadallah, D.Y. Mahmood, Z. Er, Z.A. Abdulqaedr, Acta Phys. Pol. A 130, 434 (2016).

[6] M.E. Sahin, H.İ. Okumus, A Fuzzy Logic Controlled PV-Powered Buck-Boost DC-DC Converter for Battery-Load System, INISTA Conference, Trabzon 2011.

[7] M.E. Şahin, H.I. Okumuş, J. Electrical Electron. Comput. Biomed. Engin. 3, 17 (2013).

[8] M. Boaro, D. Fuselli, F. De Angelis, D. Liu, Q. Wei, F. Piazza, Cognitive Computat. 5, 264 (2013).

[9] A. Manallah, M. Bouafia, A. Guechi, Photometric Study of a Solar Cell Panel Si-c, NuRER Conference, İstanbul 2012. 
[10] Sunrise, SR Module SR-M536100 www.srsolartech.cn, Sunrise Solar Tech Document, 1 March 2013.

[11] Electromagnetic spectrum and visible light, www.wikipedia.com, 2013.

[12] Commercial Energy, HY-400WL-600WL (5BLADES) Wind Turbines, www.newskypower.com, 2013.

[13] Z. Er, Acta Phys. Pol. A 130, 72 (2016).

[14] A.A. Jadallah, D.Y. Mahmood, Z.A. Abdulqader, Acta Phys. Pol. A 128, B-461 (2016).
[15] J. Yang, L. Gong, Y. Tang, J. Yan, H. He, L. Zhang, G. Li, Cognitive Computat. 7, 582 (2015).

[16] M.S. Kaiser, Z.I. Chowdhury, S. Al Mamun, A. Hussain, M. Mahmud, Cognitive Computat. 8, 946 (2016).

[17] M.E. Şahin, H.İ. Okumuş, Turk. J. of Electromech. and Energ. 1, 1 (2016). 